\title{
VfZ-Online $_{217}$
}

\section{Neu: Zwei weitere Beiträge in der Rubrik „VfZ Hören und Sehen“}

Unter der Überschrift „Ins Heft gezoomt“ bietet die VfZ-Redaktion in Zusammenarbeit mit dem Referat für Presse- und Öffentlichkeitsarbeit des Instituts für Zeitgeschichte seit Juli 2021 ein innovatives audiovisuelles Format an. Wir werden regelmäßig bestimmte Themen und Autorinnen beziehungsweise Autoren durch Interviews vorstellen, die in der neuen Rubrik „VfZ Hören und Sehen“ von VfZOnline archiviert werden. Bei dieser Gelegenheit erhält das Publikum auch Einblick in die anderen Inhalte der neuen Ausgaben. Für das Oktober-Heft 2021 hat VfZ-Chefredakteur Thomas Schlemmer zwei Interviews geführt: mit Morten Reitmayer (Universität Trier) über seinen kritischen Forschungsbericht „Populismus als Untersuchungsfeld der Zeitgeschichte“ sowie mit Isabel Heinemann (Universität Münster) und Martina Steber (Institut für Zeitgeschichte München-Berlin) über die von ihnen organisierte Diskussion „Geschlecht und Demokratie“. https://www.ifz-muenchen.de/vierteljahrshefte/vfz-hoeren-und-sehen/ins-heftgezoomt 